\title{
O FOMENTO AO DESENVOLVIMENTO DE LONGO PRAZO E O PAPEL DO ESTADO COMO INDUTOR DA INOVAÇÃO E DO EMPREENDEDORISMO: OS CASOS DA UNIDADE BENEFICIADORA DE LEITE DE ALAGOAS (UBL) E A NORVINCO INDÚSTRIA DE EMBALAGENS S.A.
}

\author{
Economista, Mestrado em Desenvolvimento e Meio Ambiente - PRODEMA/UFAL. \\ Analista técnico da unidade de gestão estratégica do Sebrae/AL. \\ Maceió, AL, Brasil.
}

\begin{abstract}
RESUMO - O artigo pretende demonstrar que a importância do Estado na economia como indutor e fomentador da inovação, principalmente nos estágios iniciais das pesquisas básicas. Este é um dos momentos cruciais das futuras inovações nos produtos que chegam ao mercado. É um momento decisivo para a continuidade das pesquisas e para a construção de articulações e redes de cooperação que consigam aproximar a geração de ideias com a concretude dos produtos no mercado. O componente 'incerteza' nos estágios iniciais do processo de inovação não pode ser reduzido estatísticamente a zero, dificultando os investimentos do setor privado e, como consequência, estancando o crescimento econômico e o ganho de competitividade das empresas e a elevação da renda dos trabalhadores na economia. Podemos observar a ação do Estado em dois casos específicos de empresas que se utilizaram de políticas de apoio à inovação. Os resultados apresentados evidenciam a importância da ação de políticas públicas para que a iniciativa privada aumente seus níveis de eficiência produtiva e modifiquem o estado da economia de forma ampliada.
\end{abstract}

Palavras-chave: Inovação; Políticas Públicas; Competitividade.

THE PROMOTION OF LONG-TERM DEVELOPMENT AND THE ROLE OF THE STATE AS AN INDUCTOR OF INNOVATION AND ENTREPRENEURSHIP: THE CASES OF THE ALAGOAS MILK BENEFITING UNIT (UBL) AND THE NORVINCO PACKAGING INDUSTRY S.A.

\begin{abstract}
ABSTRATC - The article intends to demonstrate that the importance of the State in the economy as an inducer and promoter of innovation, especially in the initial stages of basic research. This is one of the crucial moments of future product innovations that come to market. It is a decisive moment for the continuity of the researches and for the construction of articulations and networks of cooperation that are able to approach the generation of ideas with the concretude of the products in the market. The 'uncertainty' component in the early stages of the innovation process can not be statistically reduced to zero, hampering private sector investments and, as a consequence, stalling economic growth and corporate competitiveness gains and raising workers' economy. We can observe the action of the State in two specific cases of companies that have used policies to support innovation. The results presented highlight the importance of public policy action so that the private initiative increases its levels of productive efficiency and modifies the state of the economy in an extended way.
\end{abstract}

Key words: Innovation; Public Policy; Competitiveness.

\section{INTRODUÇÃO}

Mesmo durante um período de expansão, a maioria das empresas e bancos preferem financiar projetos e inovações incrementais e de baixo custo, esperando que o Estado deixe sua marca em áreas mais radicais. Mas, como acontece com todas as revoluções tecnológicas, os investimentos sociais precisam de um governo ousado para assumir a liderança e investir 
apoiando grupos de empresas e de produtores ávidos por assumir tarefas em parceria com o Estado. O resultado deste esforço costuma ser mais que proporcional aos investimentos iniciais e costuma gerar retornos sociais em termos de desenvolvimento e crescimento econômico.

$\mathrm{O}$ artigo pretende demonstrar que o Estado é muito importante na indução e fomento à inovação, principalmente nos estágios iniciais das pesquisas básicas. Este é um dos momentos cruciais das futuras inovações nos produtos que chegam ao mercado. É um momento decisivo para a continuidade das pesquisas e para a construção de articulações e redes de cooperação que consigam articular ideias com o mercado.

Porém, mais do que simplesmente financiar ou subsidiar as pesquisas, um novo tipo de Estado é requerido na economia. Um tipo de Estado ativo, inovador e empreendedor que possa: i) arriscar junto com os empresários; ii) participar do capital das empresas financiadas; iii) obter lucro dos investimentos realizados nas empresas privadas e, assim, retroalimentar novos financiamentos demandados pela economia.

As decisões sobre inovação trazem internamente aspectos de incerteza que não podem ser eliminados. Os agentes econômicos têm aversão ao risco e, assim, evitam, tomar decisões de investimento quando ainda não têm um horizonte claro do que podem encontrar na outra ponta deste rio revolto. A atitude de aversão ao risco por parte dos agentes econômicos privados, quando se deslocam para uma posição prudencial quanto aos investimentos, dificultam e atrapalham a inovação. O Estado tem um papel fundamental na redução dos riscos knightianos, aqueles que não podem ser reduzidos a zero e que, portanto, trazem uma incerteza intrínseca nos processos de decisão para a inovação.

A inovação demanda financiamento adequado, mas que tenha metas a serem cumpridas. Regras e normas devem ser respeitadas. Não se trata apenas de prover financiamento público para apropriação privada por meio de escolhas ou de privilégios a determinados setores da economia. As decisões de alocação de recursos públicos devem vir acompanhadas de metas, regras e normas que devem ser cumpridas e acompanhadas do início ao fim do ciclo de investimentos. Punições para o não cumprimento das metas devem ser impostas e executadas, para evitar o risco de negligência dos recursos públicos e também para evitar a aprovação de projetos frágeis em termos de promoção do desenvolvimento de longo prazo de determinada região ou país.

Levando tudo isso em consideração, o presente artigo busca apresentar o tema do financiamento à como um dos fatores primordiais para a geração de patentes e novos produtos inéditos na economia. Será apresentada uma nova forma de agir por parte do Estado ao apresentar uma forma diferente de combinar recursos com resultados. O protagonismo do Estado na economia também é apresentado a partir do esforço para reduzir os riscos e as incertezas do que se 
conhece como incerteza knightiana. A segunda seção apresenta a proposta do Estado Empreendedor e faz uma breve revisão teórica dos principais trabalhos e autores dedicados aos processos de inovação e aos métodos de transformar ideias em produtos e coloca-los no mercado.

A partir da terceira parte são apresentados dois estudos de caso de promoção da inovação, onde se buscam evidências acerca dos aspectos técnicos e teóricos relatados nas seções anteriores. Os casos tratam do lançamento de uma indústria de leite em pó que precisa do financiamento do Estado parra existir. Serão apresentados os investimentos já realizados, as necessidades de novos financiamentos e os custos que seguem existindo para a economia e a sociedade no vazio de decisão acerca do investimento. O segundo caso trata de investimentos públicos e privados no lançamento de um novo produto no mercado, gerando patentes e ampliando as receitas da empresa e da economia. O financiamento adequado potencializa a inovação e garante que o processo de ampliação de mercado, renda e lucros pode ser conseguido no arranjo de parcerias entre o setor público qualificado e o setor privado ágil e competente.

Por fim, na conclusão faremos um debate sobre o que realmente justifica a participação do Estado na economia, especificamente no processo de geração e promoção da inovação. Por que o Estado deveria participar no fomento à inovação? De que tipo de fomento estamos falando? Por que as forças de mercado não garantem e não dão conta de promover o desenvolvimento e a inovação de formas autônomas? São questionamentos que o artigo se propõe a discutir para abrir novas perspectivas de superação das dificuldades em implementar a inovação no mercado - principalmente em regiões periféricas.

\section{O PROTAGONISMO DO ESTADO NA ECONOMIA E A INCERTEZA KNIGHTIANA}

Ultimamente tem sido atitude recorrente em várias partes do mundo questionar o papel do Estado na economia. O argumento mais comum é o tradicional "redução de custos" e as usuais afirmações de que sua ausência trará mais dinamicidade à economia e a tornará mais competitiva e inovadora. O Estado deveria ficar apenas nas funções básicas de prover educação, segurança e resguardar os investimentos do setor privado: argumentos tão herméticos quanto ultrapassados!

Seguindo a linha mais afirmativa e assertiva é importante mostrar como o Estado pode fazer e realizar mais e, assim, apresentar sua face mais empreendedora e inovadora. E deve-se mostrar isso através de evidências e não somente a partir de discursos destrutivos do papel do Estado na economia. Os exemplos ao redor do mundo são diversos e em quantidade e provam justamente o contrário. Exemplo disso é o papel ativo do Estado nas incubadoras de inovação e empreendedorismo - como o Vale do Silício, a Rede de Incubadoras de Minas Gerais, os clusters de inovação de Campinas (SP) e de Eletrônica em Santa Rita do Sapucaí (MG). Nesses 
locais, o Estado não apenas facilitou e induziu a economia, mas criou o ambiente e os investimentos específicos e customizados para cada atividade.

A revolução das tecnologias verdes presentes hoje no mundo inteiro (energia solar e eólica, além da biomassa e os sistemas de fluxo fechado e economia circular) alçou ao patamar de liderança naqueles países onde o Estado não apenas direciona recursos específicos, mas onde os empréstimos estão sendo dirigidos e direcionados. Em que pese a crítica aos bancos de desenvolvimento acerca da socialização dos riscos e privatização dos benefícios, é certo que os investimentos em inovação apresentam o mesmo caráter social do retorno deste tipo de investimento. Ou seja, é preciso mostrar e evidenciar a potência dos retornos sociais dos investimentos no tocante ao fortalecimento do capital social onde os mesmos são realizados, além da criação de uma rede de organizações e novos atores que virão a fazer a diferença nas regiões mais periféricas dos estados.

O investimento do Estado na economia apresenta outro papel importante, para além de "simplesmente" fomentar start ups, capital de risco e empresas de fundo de quintal. Trata-se de verdadeiramente suprir a incapacidade dos agentes em assumir riscos e a incerteza knightiana: aquela que é verdadeiramente desconhecida e que, portanto, não se pode medir! Como afirma Mazzucato (2014): “(...) em geral, (a inovação), custa mais do que oferece como retorno, fazendo com que a tradicional análise custo-benefício breque seu desenvolvimento logo de cara”. Ora, se mesmo com este perfil de retorno sobre os investimentos as inovações costumam consumir milhões de dólares, os investimentos sociais, com geração de milhares de postos de trabalho, tributos e renda, são mais do que necessários para a promoção do desenvolvimento em regiões periféricas.

Voltando ao conceito de Frank Knight (1921), vemos que ele distingue incerteza de risco. A definição de risco refere-se a um "estado de futuro incerto, definido por meio de variável aleatória cujo estado probabilístico é perfeitamente conhecido, como, por exemplo, o lançamento de uma moeda ou de dados. Já a incerteza, embora também seja um estado futuro incerto, é definida por meio de variável aleatória, em estado probabilístico não perfeitamente conhecido, caso por exemplo, de quando será a próxima crise econômica mundial” (Teixeira, et. al, 2015).

Grande parte dos agentes, quando em situação de incerteza, preferem o risco - situação probabilística que ficou conhecida como o paradoxo de Ellsberg (1961). Os agentes preferem o risco porque este pode ser conhecido a partir de um estado probabilístico perfeitamente conhecido, como já citado anteriormente. No caso da incerteza, temos a situação singular de tomada de decisão sob o risco de probabilidades subjetivas. Os indivíduos estão, portanto, diante de eventos onde as probabilidades de ocorrência não podem ser reduzidas em $100 \%$ e, então, migram para uma posição de prudência diante do desconhecido (teoria da decisão sob incerteza). 
Os processos de pesquisa básica carregam um forte componente de incerteza, uma vez que não é possível determinar com $100 \%$ de certeza a priori, onde se chegará quando se inicia uma pesquisa científica. Não há garantias de que os esforços da pesquisa científica transformarão ideias em produtos. Se a inovação tem um forte componente de incerteza, e se os indivíduos e os agentes econômicos têm aversão à incerteza, fica claro que não será o mercado privado quem suprirá a demanda por investimentos nas fases iniciais dos processos de inovação. O Estado inovador e empreendedor se faz necessário, portanto, para fazer chegar ao mercado todos os esforços de anos de pesquisas em laboratórios ou mesmo nos esforços de criar empresas que venham a ofertar na economia o que o capital privado não está preparado para fazê-lo, seja por falta de investimento adequado, seja por falta de infraestrutura e tamanho (escala).

\section{O ESTADO EMPREENDEDOR}

\section{BREVE REVISÃO DA LITERATURA DA TECNOLOGIA E INOVAÇÃO COMO DRIVES PARA O CRESCIMENTO ECONÔMICO}

Uma das principais questões da economia é o processo de crescimento econômico e a distribuição dos seus resultados por toda a sociedade. Como forma de responder à equação do crescimento econômico, a função de produção era o caminho natural para isto. A tecnologia era tida, portanto, como um drive para o crescimento econômico e, juntamente com capital e mão de obra, respondia a todos os esforços da economia para este fim.

Quanto maiores os investimentos nos fatores de produção, maior a produtividade e, portanto, maior o crescimento econômico. Assim, o crescimento era visto como o somatório de investimentos em capital e mão de obra + ganhos de produtividade, de acordo com o modelo de Solow, $\mathrm{Y}=\mathrm{F}(\mathrm{K}, \mathrm{L})$, onde: $\mathrm{Y}=$ produto total; $\mathrm{K}=$ capital; $\mathrm{L}=$ trabalho.

No entanto, de acordo com o modelo, não mais que $90 \%$ da variação do produto econômico era respondido por capital e trabalho em uma economia industrial. Os 10\% restantes eram creditados aos ganhos de produtividade como evidência da inovação em quantidades de tecnologia. Este resíduo foi chamado de "efeito mudança técnica"; efeito esse que conseguia deslocar a curva do produto total e não provocava somente deslocamentos ao longo da curva como resultado de mais investimentos em tecnologia.

Dentro da tradição neoclássica da "cheia do mainstream" (POSSAS, 1997), o modelo de crescimento econômico de Solow foi redefinido como sendo o produto (Y) uma resultante da quantidade de capital (K) e trabalho humano (L), e foi inserida a condição de ceterisparibus - tudo o mais mantendo-se constante - para o restante. Esse "restante" que foi considerado residual, era a mudança tecnológica. Aumentos de $\mathrm{K}$ e L provocavam movimentos ao longo da curva, enquanto 
que as mudanças não explicadas (exógenas) na mudança técnica tinha o poder de gerar deslocamento para cima da curva, fazendo com que $\mathrm{K}$ e $\mathrm{L}$ fossem usados de forma mais produtiva.

Esta 'nova' abordagem - que ficou conhecida como a "teoria do crescimento exógeno" passou a considerar a variável 'mudanças técnicas' no modelo da função de produção de Solow, que se transformou em: $\mathrm{Y}=\mathrm{A}(\mathrm{t}) \mathrm{F}(\mathrm{K}, \mathrm{L})$, onde $\mathrm{A}(\mathrm{t})=$ mudança técnica como tendência temporal.

A partir do momento em que os economistas passaram a considerar de maneira mais firme o papel da tecnologia no processo de crescimento econômico, surgiu a "teoria endógena" ou "do novo crescimento" - entendendo tecnologia como P\&D $(T=f(P, D))$. Com isso, a nova forma de pensar passou a incluir P\&D e investimentos em formação de capital humano. Porém, o equívoco foi tratar as novas ideias surgidas no processo como sendo uma atividade endógena às empresas. Trata-se de um equívoco porque não leva em conta a organização institucional necessária para a transformação das ideias em produtos por dentro das empresas. As políticas públicas baseadas no modelo 'technology-push' determinam que o investimento (endógeno ou exógeno) é uma função de produção para justificar o crescimento econômico, mas não levam em conta o esforço externo às mesmas, e medem o desempenho das empresas com métricas que não retratam este esforço - como os registros de patentes, por exemplo.

Nelson e Winter (1982), com sua Teoria Evolucionária da Mudança Econômica, questionaram a função de produção como a mais adequada para capturar os ganhos econômicos e a evolução tecnológica. Sua abordagem propunha um mergulho na 'caixa preta' da função de produção para entender como a inovação ocorre e afeta a competição e o crescimento econômico. Segundo este modelo, a inovação acontece em um constante processo de diferenciação entre as empresas no mercado, e com base em suas diferentes capacidades para inovar como consequência de suas rotinas internas e competências singulares. Esta abordagem leva em conta processos como o learningbydoing (aprender fazendo) e path dependence (dependência da trajetória, que insere a noção de que a 'história importa') enquanto faces do processo de rendimentos crescentes de escala e concorrência imperfeita.

Este modelo, entretanto, incita a pergunta: quais empresas sobrevivem e crescem em detrimento daquelas que encerram suas atividades? Qual a origem das competências internas das empresas? Seriam os investimentos necessários à inovação empresarial totalmente supridos pelos próprios empresários capitalistas? Como isto seria possível se a inovação é uma variável knightiana, onde seu risco e incerteza não podem ser reduzidos em $100 \%$ das probabilidades.

\section{NECESSIDADE DE APOIO PARA FAZER O QUE NINGUÉM ESTÁ FAZENDO}

A economia tradicional considera o apoio do governo nos negócios como simplesmente uma correção de rumos. No jargão da economia, trata-se de corrigir 
externalidades negativas provocadas por algum investimento do setor privado. Da mitigação da poluição aos bens públicos de difícil apropriação - como a pesquisa básica e os investimentos de longo prazo como o esgotamento sanitário, saúde básica e outros - o apoio e as ações do governo são vistos tradicionalmente como reativos.

O que se propõe aqui, portanto, é a análise do investimento "ativo", aquele do tipo empreendedor, que coloca a sociedade em um patamar acima em termos de retornos sociais e também na criação de novas combinações de produção, novas empresas e novos negócios. Como afirmava Keynes (1926), “o importante para o governo não é fazer coisas que os indivíduos já estão fazendo, e fazê-las um pouco melhor ou um pouco pior; mas fazer aquelas coisas que no momento não são feitas de forma alguma".

Como forma de contribuir para as discussões acima, analisamos a seguir dois casos de apoio do Estado ao setor privado como uma maneira de fortalecer a inovação e a geração de novos empregos na economia. Inicialmente, analisaremos o caso da implantação de uma fábrica de leite em pó no Sertão Alagoano e, no segundo caso, a criação de um novo produto - uma embalagem sustentável e mais resistente de uma empresa privada. Ambos os casos apresentam grandes impactos na geração de postos de trabalho, modificação na estrutura de concorrência e na criação de patentes, com passagem por pesquisa básica e crédito sob medida. O papel do Estado empreendedor nos dois casos é importante para a minimização dos riscos knightianos e para a implantação de um novo modelo de desenvolvimento cooperativo entre o setor público e o setor privado em novas bases, tendo por finalidade a ampliação de novas oportunidades e renda para a sociedade.

\section{O ESTADO EMPREENDEDOR E O CASO DA UNIDADE BENEFICIADORA DE LEITE DE ALAGOAS - UBL}

A proposta de constituição de uma nova fábrica de produtos derivados do leite coloca o Estado de Alagoas em uma nova condição de competitividade na Região Nordeste e no Brasil. São poucos os empreendimentos que já nascem com uma estrutura robusta, onde são criadas condições para a sustentabilidade no longo prazo de uma cadeia produtiva que atende prioritariamente pequenos produtores de leite. O projeto atende também de forma aprofundada, à promoção de conhecimentos específicos e novos saberes para as regiões do entorno da fábrica, na cidade de Batalha, no sertão alagoano.

Estes novos conhecimentos e a necessidade de criá-los, certamente atrairá cérebros para a região e ativará novos negócios em outros elos da cadeia produtiva. O local onde o projeto será instalado, por sua vez, apresenta todas as condições de enraizamento social e externalidades positivas em vários elos da cadeia produtiva do leite e derivados. Em termos de geração 
conhecimento, a região conta com duas universidades - uma estadual e outra federal (na cidade de Arapiraca, a aproximadamente $70 \mathrm{Km}$ de distância e também em Batalha) - que contam, por sua vez, com cursos ligados à atividade produtiva em questão, além dos cursos de administração, economia e negócios. Conta também com um instituto federal (Ifal em Arapiraca, a pouco mais de $70 \mathrm{Km}$ e um também em Batalha) que pode destinar mão de obra técnica qualificada para as atividades na indústria. Portanto, a região conta com uma grande oferta de formação de cérebros e de profissionais técnicos para tocar as diversas etapas produtivas e de pesquisa e desenvolvimento. A nova planta industrial será, assim, um catalisador dessas potencialidades; atuará como um fixador de cérebros e evitará sua evasão para outros locais do estado ou do país, uma vez que os investimentos e os empregos para estes jovens já estarão em sua própria região.

A existência de um Pólo Agroindustrial na cidade de Batalha, por sua vez, proporcionará a possibilidade de construção de diversas parcerias para a realização de testes laboratoriais e pesquisas de desenvolvimento de novos produtos - reduzindo assim os custos com investimentos dentro da própria unidade produtiva. Neste momento, a fábrica potencializará os negócios do próprio Pólo, que terá a oportunidade de se viabilizar financeiramente e reduzir o custo operacional para o próprio Estado.

O projeto se apresenta como uma grande e saudável parceria público-privada, onde diversos atores são potencializados e contam com seu papel destacado junto à sociedade alagoana. Mais que isso, a parceria abre espaço de novos negócios para agências do governo e para novas empresas privadas que serão atraídas a operar na região de interesse da nova planta industrial.

\section{UMA PROPOSTA DE INOVAÇÃO E MUDANÇA}

Normalmente, os bancos de desenvolvimento atuam na economia em momentos onde atividade econômica está deprimida e o país está em crise. Seu papel clássico na minimização de riscos para o setor privado, redução de juros e irrigação da economia com crédito produtivo são pontos destacados e sobejamente pesquisados na vasta literatura sobre desenvolvimento. O caso da UBL vai muito além disso.

Trata-se do Estado agindo como força de inovação e mudança, não apenas reduzindo os riscos envolvidos na operação para os setores privados operarem, mas também assumindo a liderança com determinação, ousadia, visão clara, corajosa e empreendedora, diretamente oposta ao tradicional Estado paquiderme.

Quando o Estado faz isso por meio de um grupo de empresários ligado a grupos produtivos, entretanto, faz muito mais do que o seu papel mais arrojado. Na verdade, ele forja as condições para que uma nova combinação de produção e um novo grupo diferenciado possa surgir em uma 
região deprimida e periférica. Faz isso ao encorajar o setor privado a investir mais que proporcionalmente, valorizando seus recursos e os colocando na situação de meros alavancadores de valores muito maiores e de atrator de novos parceiros com novos investimentos.

O projeto da UBL já conta com recursos de mais de $\mathrm{R} \$ 40$ milhões de reais (obtidos por meio de investimentos privados e de recursos públicos federais) e alavanca apenas $\mathrm{R} \$$ 13 milhões diretamente do Estado de Alagoas. Uma proporção vitoriosa e que poderá promover novas rendas futuras, uma vez que não se trata de um investimento estático, mas sim do investimento semente, o capital necessário para fazer iniciar uma produção que terá o caráter social e empreendedor ao mesmo tempo. O Estado está, portanto, encorajando o setor privado a investir e ativar uma cadeia produtiva que movimenta todas as regiões do Estado e mobiliza milhares de produtores, suas famílias, gestantes, educandos e idosos, que recebem o leite por meio de programas de cunho social.

Com a indução dos investimentos do setor privado, o atual projeto da UBL derruba outro grande fenômeno da economia - o denominado crowding out. Este fenômeno diz respeito à possibilidade de que a elevação nos gastos do Estado podem reduzir os investimentos do setor privado, uma vez que ambos competem pelo mesmo conjunto de poupança (via doação e empréstimos), o que poderia resultar em taxas de juros mais elevadas, reduzindo a disposição das empresas para tomar empréstimos e investir. Ora, se o que se está demandando com a presente proposta significa apenas uma parte do todo - algo como $28 \%$ do total dos investimentos para iniciar a produção - significa que o setor privado não está diminuindo seu apetite por investimentos.

Ao contrário, o governo está conseguindo ativar seu "espírito animal" e fazer com que novos e maiores investimentos sejam programados e efetivados. Dessa forma, o que o governo está provocando é o crowd in do investimento privado, aumentando a receita local através do efeito multiplicador dos recursos liberados.

Assim, o efeito provocado pelo Estado é ativo, positivo e empreendedor e não burocrático e dificultador. Com a indução de investimentos inovadores, o Estado reúne e dinamiza os investimentos privados, criando a visão, a missão e, em alguns casos, o plano. Ou, em outras palavras, influenciando essas etapas para que ela aconteça por meio do incentivo e criação de grupos produtivos cooperativos e executivos, que reúnem competência e habilidade para gerenciar um empreendimento da envergadura ora analisada.

Complementando o ciclo da proposta, a UBL propõe a interveniência da Agência de Fomento do Estado como o elo financeiro do projeto. A Agência tem o importante papel de ser uma ponte entre a produção e o mercado, ao ativar sua capacidade de canalizar recursos para as 
iniciativas portadoras de futuro. Adicionalmente, poderá colher recursos para suas atividades de fomento - ao acompanhar os investimentos em sua implantação e funcionamento - por meio das taxas de projetos e também através das carteiras de clientes construídas pela UBL e disponibilizadas aos agentes financeiros da Agência.

O projeto, portanto, não apenas viabiliza seu próprio investimento, mas vai além. Viabiliza também a cadeia produtiva de leite e derivados do Estado de Alagoas, os investimentos em infraestrutura de tecnologia para a região, atrai e induz novos investimentos e alavanca financeiramente os organismos do governo que dão suporte às atividades empresariais alagoanas.

A seguir apresentamos as propostas de captação e devolução dos recursos à sociedade alagoana, evidenciando assim mais do que um retorno financeiro, mas antes, uma Política Pública de fomento à criação de novas empresas e também de fomento ao desenvolvimento regional.

\title{
OS RECURSOS DO FECOEP
}

No que diz respeito à utilização dos recursos do Fundo Estadual de Combate e Erradicação à Pobreza - FECOEP, analisa-se como de total enquadramento ao que preconiza a Lei Estadual $n^{\circ} 6.558$, de 30 de dezembro de 2004, o Decreto $n^{\circ} 2.845$, de 14 de outubro de 2005. Em seu artigo $1^{\circ}$, a Lei de Criação do FECOEP dispõe:

\begin{abstract}
Art. $1^{\circ}$ Fica instituído, no âmbito do Poder Executivo Estadual, o Fundo Estadual de Combate e Erradicação da Pobreza - FECOEP, com o objetivo de viabilizar para toda a população de Alagoas o acesso a níveis dignos de subsistência, cujos recursos serão aplicados exclusivamente em ações suplementares de nutrição, habitação, educação, saúde, saneamento básico, reforco de renda familiar e em outros programas de relevante interesse social, voltados para a melhoria da qualidade de vida (grifo nosso), conforme disposto no art. 82 do Ato das Disposições Constitucionais Transitórias - ADCT da Constituição Federal.
\end{abstract}

É importante salientar que nas competências do Conselho Consultivo de Políticas de Inclusão Social do Fecoep - CIPIS (artigo $5^{\circ}$, inciso I) fica evidenciado que a presente proposta toma a forma de uma ação voltada para a redução da pobreza e das desigualdades sociais. E, no artigo $6^{\circ}$ da referida lei de criação do FECOEP (que trata da Política Estadual de Combate à Pobreza), entende-se que todos os incisos fortalecem e fundamentam o projeto.

Com relação ao Plano Estadual de Combate à Pobreza, de elaboração do CIPIS, temos os seguintes enquadramentos:

$1^{\circ}$ As diretrizes que orientam as ações de combate à pobreza do Governo do Estado são aquelas definidas na Lei $\mathrm{n}^{\circ} 6.558$, de 30 de dezembro de 2004, quais sejam:

- Superação da pobreza e redução das desigualdades sociais;

- Acesso de pessoas, famílias e comunidades a oportunidades de desenvolvimento integral;

REVISTA ECONOMIA POLÍTICA DO DESENVOLVIMENTO $\quad$ Maceió - AL $\quad$ V.3 N.5. $\quad$ DEZEMBRO/2016 P.1-21 Página-10


- Geração de oportunidades econômicas e de inserção de pessoas na faixa economicamente ativa no setor produtivo e combate aos mecanismos de geração da pobreza e de desigualdades sociais.

Somam-se a essas diretrizes duas recomendações de caráter social, que também deverão ser observadas na conceptualização de um novo Programa/Projeto:

- Justiça social - as realizações do programa deverão promover acesso adequado a necessidades de grupos e populações em situações de pobreza, contribuindo para a diminuição das desigualdades sociais; $\mathrm{e}$

- Reconhecimento das diferenças e Igualdade de direitos - essa recomendação é complementar à justiça social e busca estimular a promoção da igualdade de direitos, incentivando a realização de ações afirmativas.

Em seus objetivos específicos, o Plano Estadual de Combate à Pobreza reforça a atual proposta ao citar textualmente:

- Construir e consolidar alternativas de crescimento e desenvolvimento, com responsabilidade ambiental, que respondam às necessidades sociais e econômicas da população pobre do estado de Alagoas, gerando emprego e renda;

- Contribuir para a desconcentração espacial do PIB alagoano, estimulando o crescimento e a desconcentração econômica;

- Estimular o fortalecimento de redes sociais e econômicas;

- Possibilitar o acesso aos direitos socioassistenciais;

- Contribuir para a redução dos déficits sociais em especial aqueles relacionados com educação, saúde, sub-registros, habitação, priorizando a atenção aos grupos historicamente excluídos como: mulheres, negros, índios, quilombolas;

- Promover melhorias na qualidade da gestão pública, tornando-a mais eficiente e moderna e promoção de espaços de concertação e diálogo entre o governo e a sociedade civil com vistas à construção de uma nova cultura política;

- Incentivar a organização social e participação nos espaços de gestão pública.

Em outro item do Plano Estadual de Combate à Pobreza, quando trata dos projetos de Inclusão Social, o documento afirma que:

(...) o investimento em ações de infra-estrutura, serviços sociais e desenvolvimento comunitário serão prioridades dentro das ações a serem implementadas nesse eixo. Essas ações devem possibilitar à população pobre aumentar seu acesso aos serviços 
básicos e às oportunidades de melhoria de vida. Isso significa a realização de investimentos na área da habitação, água, saúde, escolas, centros de qualificação profissional, registros e documentos de identificação, assistência a vítimas de violência, com destaque para a violência contra a mulher, gravidez na adolescência, protagonismo juvenil, entre outras medidas, que venham a contribuir para a cidadania ativa, favorecendo a construção do capital social e humano.

Diante de todos esses pontos, fica claro que a proposta está totalmente aderente ao que preconiza a Lei de Criação do Fecoep. Adicionalmente ao que nos informa a Lei e o Plano Estadual de Combate à Pobreza, percebe-se que o Estado de Alagoas tem a oportunidade de construir e apresentar um perfil empreendedor que apoia projetos desta magnitude.

Em que pese todos os argumentos favoráveis à construção de um Estado Empreendedor, no entanto, a proposição deste novo projeto não resultou ainda na captação dos recursos necessários ao início das operações da UBL. Segundo informações da Cooperativa de Produção Leiteira de Alagoas - CPLA (proponente da criação da UBL), ainda não se chegou a um denominador comum acerca da transferências de recursos e da forma de gestão para a implantação da referida fábrica.

\section{O CASO DA NORVINCO INDÚSTRIA DE EMBALAGENS E O SUBSÍDIO À INOVAÇÃO}

\section{O PROGRAMA INOVACRED COMO INSTRUMENTO DE INDUÇÃO À INOVAÇÃO EMPRESARIAL}

O Programa INOVACRED destina-se ao apoio a empresas e outras instituições que apresentem projetos de inovação. É um instrumento criado pela Finep (Financiadora de Inovação e Pesquisa, instituição ligada ao Ministério da C, T\&I) e repassado a bancos e agências de fomento através de contratos específicos, onde são definidos objetivos comuns e métricas de performance.

Conforme o portal da Finep na internet ${ }^{1}$, o objetivo do Programa INOVACRED é oferecer financiamento a empresas de receita operacional bruta anual ou anualizada de até $\mathrm{R} \$ 90$ milhões, para aplicação no desenvolvimento de novos produtos, processos e serviços, ou no aprimoramento dos já existentes, ou ainda em inovação em marketing ou inovação organizacional visando ampliar a competitividade das empresas no âmbito regional ou nacional ${ }^{2}$.

Em Alagoas, o INOVACRED é operacionalizado pela Agência de Fomento de Alagoas S.A. (Desenvolve) e contou com repasses iniciais na ordem de $\mathrm{R} \$ \mathbf{5 . 0 0 0 . 0 0 0 , 0 0}$ (cinco milhões de reais) para investimentos em projetos de inovação empresarial no Estado. A

\footnotetext{
${ }^{1}$ www.finep.gov.br

${ }^{2}$ Todas as informações, regras e limites operacionais do Inovacred podem ser encontrados no portal: www.finep.gov.br, no perfil empresas (programa Inova, descentralização).
} 
Norvinco Indústria de Embalagens foi uma das primeiras empresas a se candidatarem ao financiamento para a introdução de um novo produto na economia. $O$ caso da referida empresa está resumido abaixo, com análises sobre a importância do papel do fomento atuando junto com o processo de governança e monitoramento de todas as fases do processo. Falhas no processo de monitoramento e mesmo a inexistência do subsídio e customização dos instrumentos de crédito direto à inovação, podem frear o processo de crescimento econômico e de geração de valor para a economia, como poderá ser verificado.

\section{CARACTERIZAÇÃO DA EMPRESA}

A Norvinco Indústria de Embalagem do NE Ltda foi constituída em 16/08/1993, e tem como representantes legais o casal Maria Cristina Hassenstein - Diretora Administrativo Financeira, formada em Comunicação Social, com especializações em Marketing Industrial e Gestão Empresarial (FGV); e JurgHassenstein - Diretor Comercial, arquiteto, com especialização em Desenvolvimento e Gestão de Projetos. O empresário participou do grupo de arquitetos suíços responsáveis pela sede da H. Stern no Estado do Rio de Janeiro e, desde então reside no país.

A Norvinco está instalada no Distrito Industrial Governador Luiz Cavalcante, na cidade de Maceió/AL, em uma área total de $6.000,00 \mathrm{~m}^{2}$ e com uma área construída de 2.374,93 m². $\mathrm{Na}$ unidade fabril conta uma equipe de desenvolvimento de projetos e produtos, locada em uma área de $45,81 \mathrm{~m}^{2}$, que se juntou à pesquisadora do Programa Inova Talentos. A Norvinco utiliza a ferramenta BSC - Balance Scorecard, para gestão de seus resultados e o setor de desenvolvimento de produtos possui indicadores de desempenho para mensurar a inovação. Para desenvolvimento dos projetos conta com o software especializado em embalagens mais popular do mundo, o ArtiosCad, onde é possível trabalhar as etapas de produção desde a seleção do papelão ondulado, passando pela visualização 3D da embalagem, até o final do processo com os mockups e, posteriormente, o encaminhamento para a produção.

O controle da empresa é genuinamente nacional, apesar de um dos fundadores ser um franco-suíço radicado em Alagoas desde a sua fundação. Seu capital social integralizado é da ordem de $\mathrm{R} \$ 568.000,00$ (quinhentos e sessenta e oito mil reais), e seu patrimônio líquido é de $\mathrm{R} \$ 224.941,86$ (duzentos e vinte e quatro mil, novecentos e quarenta e hum reais e oitenta e seis centavos). A empresa contava em 2015, no momento da proposta, com 44 funcionários e um faturamento de $\mathrm{R} \$ 5.765 .331,17$ (cinco milhões, setecentos e sessenta e cinco mil, trezentos e trinta e hum reais e dezessete centavos) ${ }^{3}$.

\footnotetext{
${ }^{3}$ Todos os números são do ano de 2015 e estão disponíveis na Agência de Fomento de Alagoas S.A. (Desenvolve). Grande parte das informações sobre o caso, recursos captados e prêmios recebidos pela Norvinco, encontram-se
} 
Em dezembro de 2013 a Norvinco participou da $1^{\text {a }}$ Chamada Nacional de Projetos IEL/CNPq - Inova Talentos - Programa Rhae Trainee CNPq/IEL, e conseguiu em junho/2014 uma bolsista pesquisadora na área de PD\&I durante doze meses. Tem parceria com a UFAL para os processos de pesquisa, desenvolvimento e inovação - P\&D\&I. Nesta primeira chamada, a empresa requereu uma patente (UM 8700537-9 U): bandeja para pallet de papelão ondulado. A patente de modelo de utilidade refere-se a uma bandeja separadora de papelão ondulado para permitir o empilhamento de garrafas dispostas sobre pallets.

Conforme já informado anteriormente, a Norvinco é uma empresa inovadora desde a sua fundação e trabalha com produtos diferenciados - seja por razões ambientais, seja por inovação para a redução de custos, ou ainda pelas duas coisas conjuntamente. Por outro lado, a empresa inova por necessidade, por conta da forte concorrência em seu setor de atividade. Por sua natureza, a empresa trabalha sob encomenda e não tem um portfólio rígido de produtos. Daí, se pode perceber que para cada nova demanda a empresa reúne sua equipe de criação e monta seus modelos, realiza testes de qualidade, elabora lay-outs e projetos piloto. E para projetos de inovação de produto, a empresa aciona suas parcerias com universidades e o Sistema FIEA (Federação da Indústria do Estado de Alagoas) para utilizar seus laboratórios, técnicos e pesquisadores para auxiliá-los no desenvolvimento dos novos produtos e novos compostos. Portanto, é rotina da empresa investir sempre em P\&D\&I (pesquisa, desenvolvimento e inovação), com a aquisição de softwares, equipamentos, consultoria e viagens internacionais para feiras, eventos e parques tecnológicos para identificar as mais recentes tendências em sua área de atuação.

A decisão acerca dos novos investimentos é tomada por um board comandado pelos sócios majoritários da empresa. Adicionalmente, participam deste grupo: consultores associados; pesquisadores; técnicos da empresa das áreas de design e produção. As reuniões são moderadas pelos sócios e todas as decisões são documentadas e acompanhadas por todos. A partir das discussões técnicas, os sócios ponderam e decidem acerca dos novos investimentos.

A empresa investe aproximadamente $20 \%$ de seu faturamento em novos negócios. Adicionalmente tem como estratégia a captação de recursos não reembolsáveis para a complementação dos investimentos, como os recursos anteriormente captados junto à FINEP e SEBRAE.

A Norvinco está à frente da concorrência na região por conta da sua necessidade de atualização constante e lançamento contínuo de novos produtos. Isto a coloca em posição de destaque em nível regional e nacional, além de servir de atratividade para eventuais parceiros internacionais.

largamente divulgados em diversas reportagens na imprensa alagoana. Para maiores informações, pesquisar em: $\underline{\text { www.gazetaweb.globo.com e a página da empresa: www.norvinco.com.br. }}$ 
Sua estratégia de inovação é pautada em pesquisas de novos materiais e novos produtos, além da preocupação constante com o mercado consumidor e seus concorrentes. A Norvinco se utiliza dos dois modelos básicas de inovação em sua estratégia empersarial: Science-push e Demand-pull.

A gestão da inovação é realizada a partir da criação de grupos técnicos específicos por projetos e por atividades. Participam destes grupos: os sócios; os consultores; as universidades; os pesquisadores e as empresas associadas. Assim, a empresa tem a oportunidade de captar informações qualitativas de grupos formados por profissionais de excelência em suas respectivas áreas de conhecimento.

\section{O PROJETO INOVADOR E A DEMANDA DE CRÉDITO PARA INOVAÇÃO: O INOVACRED}

O projeto proposto e financiado visava a substituição de embalagens de poliestireno expandido (EPS; isopor, marca registrada da Knauf Isopor Ltda) e estiropor (Estiropor Nordeste Ind. e Com. Ltda), por caixa de papelão ondulado com isolamento térmico.

O novo projeto tem uma utilização direta para o mercado de embalagem para medicamentos e lâmpadas frias, mantendo as características de conservação térmica e resistência no transporte de produtos frágeis. A proposta refere-se a inovação de produto, com a pesquisa de novos compostos ambientalmente sustentáveis. Pretende-se com a inovação proposta que a empresa alcance penetração nacional e também prepare seu caminho para demandas internacionais. Os principais benefícios do novo produto são seguintes:

- Redução de $70 \%$ do volume de estocagem, impactando no custo logístico com transporte e combustível;

- Ganho ambiental com a diminuição da poluição atmosférica;

- Utilização de isolantes térmicos feitos a partir de materiais biodegradáveis e totalmente recicláveis;

- Projeção nacional e internacional da Norvinco;

- Conhecimento técnico e científico em novos materiais para o lançamento do novo produto em substituição à embalagem poluidora (isopor).

Com relação aos resultados esperados, podemos citar:

\footnotetext{
${ }^{4}$ Science-push ou technology-push: modelo de inovação linear baseado na tecnologia. Demand-pull: modelo de inovação a partir da demanda de mercado.
} 
- Diminuição ou eliminação da utilização de embalagens potencialmente poluidoras e otimizaçãodos custos com o transporte de medicamentos e alimentos nacional e internacionalmente;

- Aumento de produtividade na ordem de $10 \%$;

- Aumento do faturamento em $25 \%$ na linha de produtos atuais e um aumento de $20 \%$ no faturamento total da empresa;

- Aumento na geração de empregos em 30\%;

- Através da concessão de patentes pretende-se incrementar o faturamento em $30 \%$ do volume projetado para 2014.

Com relação ao mercado, a introdução da inovação visa provocar um deslocamento da posição dos concorrentes com a condução da Norvinco a uma situação de liderança de mercado, lastreada por sua patente de inovação do produto desenvolvido. Os concorrentes perderão fatias de mercado por não apresentarem produto semelhante e terão de se submeter ao pagamento de royalties pela utilização do produto novo.

\section{DIFICULDADES ENCONTRADAS E O PAPEL DO FINANCIAMENTO PÚBLICO SUBSIDIADO}

Para uma empresa localizada fora dos pólos tradicionais do eixo sul-sudeste é muito difícil se manter na liderança de um mercado altamente competitivo como o segmento de embalagens para produtos frágeis. Ainda mais quando a empresa em questão trabalha com processos inovativos e apresenta diferenciais competitivos em termos de materiais, priorizando sempre aqueles menos agressivos ao meio ambiente.

A articulação para a inovação é também um fator de grande dificuldade, uma vez que os laboratórios mais bem equipados encontram-se em outras localidades, ocasionando custos significativos nos momentos iniciais de pesquisa e teste de insumos. Especificamente para o projeto submetido ao financiamento pelo INOVACRED, os desafios mais significativos enfrentados pela empresa foram:

- O desenvolvimento de um isolante térmico ecológico que atendesseàs necessidades do projeto e do meio-ambiente obedecendo as normas da legislação vigente;

- Desenvolver uma embalagem adequada ao transporte de forma plana com um custo compatível e atrativo para o mercado;

- Concorrência com os fornecedores de matéria prima;

- Disponibilidade de financiamento e prazos adequados;

- Disponibilidade de equipes especializadas e multidisciplinares;

- Articulação de parcerias para a ampliação do projeto. 
Com relação ao financiamento adequado à pesquisa, praticamente não havia alternativas anteriores ao INOVACRED que pudesse atender a empresas do porte da Norvinco. As alternativas disponíveis poderiam ser acessadas através de bancos de grande porte (como o BNDES) ou através de recursos disponíveis em editais de subvenção econômica. As alternativas pela via bancária resultavam infrutíferas, uma vez que esses bancos costumam financiar projetos de grande porte e empresas com faturamento muito elevado.

A alternativa dos recursos de subvenção econômica não são adequados ao tipo de projeto que liga a produção com o mercado. Normalmente, os editais de fomento à inovação apoiam ações de pesquisa básica, contratação de consultores, modelagem e prototipagem e outros itens, mas não contemplam rubricas como capital de giro e pesquisas de mercado, apenas para citar dois casos. A quantidade de recursos destinada por esta via também costuma ser diminuto em relação à demanda das empresas. Tanto é assim, que a Norvinco já havia participado e vencido alguns editais de fomento à inovação, mas precisava de valores maiores para concretizar seu intuito de lançar um novo produto e ampliar seu escopo de atuação no mercado.

A conjugação do lançamento do INOVACRED por um lado, com recursos, prazos e taxas adequados, e a operacionalização destes recursos por meio das agências de fomento estaduais facilitaram sobremaneira o acesso a financiamentos apropriados a impulsionar os processos de inovação empresarial.

As características do investimento aprovado pela Norvinco (ver abaixo) comprovam a adequação da demanda à disponibilidade de crédito. Com estas condições, a empresa teve condições de implementar seu projeto e lançar o novo produto dentro dos prazos acordados.

\section{RESUMO DO INVESTIMENTO}

- Valor Total do Projeto: $\mathrm{R} \$ 1.172 .040,00$

- Aporte Desenvolve/Finep: R\$1.036.270,00

- Contrapartida Financeira (excluindo as garantias reais): R \$ 162.940,00

- Prazo de Carência: 02 anos

- Prazo de Amortização dos Investimentos: 06 anos

- Prazo de Desenvolvimento da Pesquisa e Produto no Mercado: 02 anos (mesmo prazo da carência)

- Prazo Total: 08 anos

\section{CONCLUSÃO}

É lugar comum na literatura econômica a aversão ao emprego de recursos públicos para a promoção da inovação e do estado de desenvolvimento de longo prazo. Isto ocorre principalmente em momentos de crise econômica e de déficits consideráveis na economia como o que o país está passando na atualidade. A degeneração das contas públicas e o 
crescimento da pobreza e do desemprego como consequências imediatas, são situações que colocam qualquer esforço de investimento na vala comum dos cortes de recursos.

Em momentos como esses, o discurso corrente é sempre o da racionalidade econômica. $\mathrm{Ou}$ seja, ajustes fiscais e tributários, cortes nos custos de todas as ordens e priorização de recursos para o pagamento das dívidas contraídas em períodos anteriores. Todos os esforços no rumo de políticas públicas em prol do desenvolvimento e da inovação perdem espaço para as ações 'racionalizantes' de curto prazo. Com isso, o fosso do subdesenvolvimento só tende a aumentar: sem recursos, não se investe em educação, pesquisa e desenvolvimento. Na ausência destes investimentos, o país acaba por 'queimar navios' do desenvolvimento futuro. Quando, enfim, chegamos no futuro com o fim das crises econômicas, nos encontramos cambaleantes e sem capacidades acumuladas em termos de conhecimentos e novas ideias capazes de transformar a nossa realidade.

A falta de prioridades e de um projeto claro sobre onde se quer chegar, perde-se a oportunidade de construir alternativas à falta de recursos. Neste ambiente inóspito surge a primeira grande dificuldade dos projetos de inovação: como encontrar recursos para investir onde não se pode garantir com exatidão a efetividade dos retornos destes investimentos? A dificuldade, no entanto, não é apenas de recursos. Esta dificuldade, aliás, foi criada quando da decisão de não investir em segmentos da economia que estão fora do apelo da economia ortodoxa de curto prazo de pagamento de dívidas e outras obrigações orçamentárias. As incertezas knightianas da inovação não serão jamais combatidas com atitudes reativas como essas, posto que os riscos da inovação não diminuem com o tempo. Ao contrário, somente com novos recursos e a acumulação de conhecimento, construção de redes de relacionamento e de uma vasta ambiência potencializadora dos resultados dos projetos é que será possível minimizar os riscos associados.

A promoção do Estado empreendedor, portanto, passa mais por decisões estratégicas e duradouras do que somente por questões financeiras e orçamentárias. As ações de captação de recursos e ampliação do escopo de atuação do Estado na promoção da inovação vão desde o financiamento direto às empresas privadas, passando por concursos públicos de projetos, até a construção de parcerias e articulações público-privadas de várias ordens. $\mathrm{O}$ arcabouço institucional-normativo do país precisa ser refundado para que a obediência às regras e aos compromissos com os resultados pactuados nos projetos seja, de fato, cumprida. É preciso um compromisso genuíno com os resultados e um forte investimento em instrumentos de gestão e de compliance, de modo que tenhamos mais transparência e controle dos recursos aplicados. As atuais tecnologias de gestão e o novo mundo digital das indústrias 4.0, juntamente com a revolução dos sensores, apresentam um conjunto de convergência de saberes de diversas áreas que ajudam e suportam os investimentos. 
Os dois casos apresentados neste artigo refletem as situações discutidas acima. A proposição de implantação de uma nova fábrica de leite em pó na região da bacia leiteira de Alagoas, apresenta componentes de inovação em diversas etapas de seu projeto. Em que pese o fato de que a produção de leite em pó per se não configura inovação de produto (este fato pode mudar no futuro, a partir de pesquisas e desenvolvimento para o lançamento de produtos diferenciados), a simples iniciativa da implantação da fábrica mobilizará investimentos e conhecimentos que transformará a região.

As universidades e os centros de pesquisa já existentes e toda a cadeia produtiva do leite no Estado serão revitalizados e outros elos da cadeia poderão ser potencializados, como as fábricas de embalagens, empresas de logística e a vasta rede do comércio varejista e atacadista de alimentos. Os projetos sociais do governo que subsidiam o preço do leite para doação a populações carentes e em situação de vulnerabilidade, por outro lado, também justificam os investimentos necessários à abertura do empreendimento. No entanto, as decisões de investimentos complementares ainda não foram tomadas e a fábrica segue sem funcionar. As indefinições passam por falta de clareza no arranjo institucional de gestão do empreendimento e sobre as garantias nos resultados propostos em contraposição aos investimentos demandados.

O caso da indústria de papelão, por outro lado, conseguiu alcançar seu objetivo com a captação de recursos para inovação pela via de um empréstimo com recursos subsidiados. Os recursos foram captados na Agência de Fomento do Estado, a partir de recursos transferidos pela Financiadora de Projetos do Governo Federal. Ou seja, trata-se de recursos customizados para a inovação, em termos de volume, prazos e garantias. No entanto, mesmo sob condições especiais de apoio à inovação, verificamos que a empresa ainda apresentou dificuldades instrumentais no cumprimento das metas inicialmente pactuadas. Uma das principais dificuldades verificadas diz respeito ao cumprimento dos prazos nos processos iniciais da pesquisa básica. A demora em contratar consultores, a dificuldade em encontrar laboratórios com estrutura para a realização dos primeiros testes e as mudanças nas equipes do projeto, foram fatores de aprendizagem ao processo - lições aprendidas para as próximas etapas e novos investimentos a serem captados.

O acompanhamento de perto de todas as fases do projeto pela agência de fomento, demonstra a importância da gestão dos recursos e aponta para uma governança diferente nos processos de financiamento. Ou seja, não se trata apenas de prover financiamento adequado, mas principalmente prover as condições necessárias em termos de ambiente de suporte (redes de laboratórios, universidades, pesquisadores, consultores, etc.) e de acompanhamento gerencial para que os projetos tenham êxito.

Essas novas combinações de apoio - do início ao fim dos projetos e sua retroalimentação - são o que, de forma prática, promovem acesso a futuros diferentes. A construção deste novo 
arranjo pode contribuir para a redução do risco inovação, com um ambiente transparente na aplicação de recursos e também com o reforço dos ambientes de apoio às empresas.

Entendemos, por fim, que esta agenda de suporte aos investimentos a partir de um Estado ativo na condução de novos arranjos institucionais e normativos pró-inovação precisa ser aprofundada. Não se trata apenas de prover a continuidade de subsídios ao setor privado mas, antes, de construir condições institucionalizadas de suporte atemporal com a construção de fundos e outros arranjos mitigadores de risco e com governança profissionalizada.

\section{REFERÊNCIA BIBLIOGRAFICA}

ARÉVALO, A. B. El capital social como recurso de desarrollo. In. Gestión y promoción Del desarrollo local. Universitat de València, 2009. (mimeo).

BARQUERO, A. V. Desarrolloendogeno y globalizacion. Artigo publicado em Madoery, Oscar y VázquezBarquero, Antonio (Eds.). Transformacionesglobales, instituciones y políticas de desarrollo local. Editorial Homo Sapiens, Rosario, 2001.

BIELSCHOWSKY, R. Pensamento econômico brasileiro: o ciclo ideológico do desenvolvimentismo. Rio de Janeiro: Ipea; Inpes; 1988.

BRESSER-PEREIRA, L. C. Desenvolvimento e crise no Brasil: história, economia e política de Getúlio Vargas a Lula. São Paulo: Ed. 34, 2003.

CAlIXTRE, A. B.; BIANCARELli, A.M.; CINTRA, M.A.M. (editores). Presente e futuro do desenvolvimento brasileiro. Brasília:IPEA, 2014.

CHRISTENSEN, C. M.; RAYNOR, M. E. The innovator's solution: creating and sustaining successful growth. Boston: Harvard Business School Press, 2003.

FRIEDMAN, Milton. Livre para escolher. Rio de Janeiro: Record, 2015.

FURTADO, C. O capitalismo global. São Paulo: Paz e Terra, 1998.

IBGE - Instituto Brasileiro de Geografia e Estatística. PINTEC - Pesquisa Industrial de InovaçãoTecnológica. Disponível em: <http://www.pintec.ibge.gov.br> Acesso em: 21 dez. 2010

KIM, L. Da imitação à inovação: a dinâmica do aprendizado tecnológico da Coreia. Campinas, SP: Editora da UNICAMP, 2005.

KIM, L; NELSON, R. R. (orgs). Tecnologia, aprendizado e inovação: as experiências das economias de industrialização recente. Campinas, SP: Editora da UNICAMP, 2005.

LEITE, L. A. M.; SANTIAGO, L.P.; TEIXEIRA, J.P. Opções reais sob incertezaknightiana na avaliação econômica de projetos de pesquisa e desenvolvimento (P\&D). Artigo publicado em: http://dx.doi.org. Production produção, julho/setembro, 2015.

MAZZUCATO, Mariana. O estado empreendedor: desmascarando o mito do setor público vs. setor privado. São Paulo: Portfolio-Penguin, 2014.

NELSON, R. R.; WINTER, S. G. Uma teoria evolucionária da mudança econômica. Campinas: Ed. da Unicamp, 2005

OCDE, FINEP. Manual de Oslo: diretrizes para coleta e interpretação de dados sobre inovação. $3^{\mathrm{a}}$ edição. Brasília: FINEP, 1997.

PENROSE, E. A teoria do crescimento da firma. Campinas, SP: Editora da UNICAMP, 2006.

PEREZ, C. Technological revolutions and financial capital: the dynamics of bubles and Golden ages. England: Edward Elgar Publishing, 2002.

PIKETTY, Thomas. Capital in the twenty-first century. Cambridge, Massachussets, 2014.

REVISTA ECONOMIA POLÍTICA DO DESENVOLVIMENTO $\quad$ Maceió - AL $\quad$ V.3 N.5. $\quad$ DEZEMBRO/2016 P.1-21 Página-20


O FOMENTO AO DESENVOLVIMENTO DE LONGO PRAZO E O PAPEL DO ESTADO COMO INDUTOR DA INOVAÇÃO E DO EMPREENDEDORISMO:

ROSEnBERG, N. Por dentro da caixa preta: tecnologia e economia. Campinas, SP: Editora da UNICAMP, 2006.

SENAI. Desenvolvimento, inovação e sustentabilidade: contribuições de Ignacy Sachs. Rio de Janeiro: Gramond, 2014.

SCHUMPETER, J. A. Teoria do desenvolvimento econômico: uma investigação sobre lucros, capital, crédito, juros e o ciclo econômico. 3. ed. São Paulo: Nova Cultural, 1988.

TAVARES, M.C. Acumulação de capital e industrialização no Brasil. Campinas: Editora UNICAMP, 1986. 